\title{
Analisis Tabungan Paket Lebaran Dalam Persfektif Ekonomi Syari'ah di Desa Parung Kecamatan Subang Kabupaten Subang
}

\author{
Idah Hamidah $^{1}$, Jalaludin ${ }^{2}$, Ahmad Damiri ${ }^{3}$ \\ ${ }^{1}$ STAI Riyadhul Jannah Subang \\ ${ }^{23}$ STIES Indonesia Purwakarta \\ ${ }^{1}$ hamidahidah61@gmail.com \\ 2jalaludin.darululum@yandex.com \\ 3ahmad.damiri86@gmail.com
}

\begin{abstract}
Abstrak-Artikel ini membahas tentang Analisis tabungan paket lebaran dalam persfektif ekonomi syari'ah di Desa Parung Kecamatan Subang Kabupaten Subang. Tujuan dari penelitian ini adalah untuk mengetahui system akad yang digunakan dalam pelaksanaan tabungan paket lebaran di Desa parung Kecamatan Subang Kabupaten Subang, tinjauan ekonomi syariah terhadap pelaksanaan tabungan paket lebaran di Desa parung Kecamatan Subang Kabupaten Subang, dan dampak pelaksanaan tabungan paket lebaran di Desa Parung Kecamatan Subang Kabupaten Subang, Metode penelitian yang digunakan adalah penelitian kualitatif dengan pendekatan empiris. Teknik pengumpulan data yang digunakan adalah observasi, wawancara, dan dokumentasi. Dalam penelitian ini, sumber data terdiri dari Data Primer dan Data Sekunder. Data Primer diperoleh dari hasil lapangan dengan cara observasi dan wawancara langsung dengan pengelola dan anggota paket lebaran di Desa Parung Kecamatan Subang Kabupaten Subang. Data sekunder diperoleh dari berbagai referensi, seperti sumber dari internet, arsip-arsip lembaga dan bacaan lain yang berhubungan dengan masalah yang diteliti. Hasil penelitian menunjukan bahwa pelaksanaan Tabungan Paket Lebaran di Desa Parung Kecamatan Subang Kabupaten Subang menggunakan akad Wadi'ah (tabungan) sekaligus akad Salam (paket), menurut ekonomi syari'ah transaksi semacam ini tidak sah, karena islam melarang dalam satu transaksi terdapat dua akad sekaligus. Namun kehadiran tabungan paket lebaran, sangat memberikan kontribusi yang positif bagi masyarakat, maka sebaiknya pengelolaannya disesuaikan dengan prinsip-prinsip syari'at Islam. Diantaranya memisahkan transaksi tabungan dan paket lebaran.
\end{abstract}

Kata Kunci - Tabungan, Paket lebaran, Ekonomi Syariah.

\begin{abstract}
This article discusses the analysis of Eid package savings in sharia economy perspective in Parung Village, Subang Subdistrict, Subang Regency. The purpose of this study was to determine the contracting system used in the implementation of Eid savings packages in Parung Village Subang Subdistrict, Subang Regency, Sharia economic review of the implementation of Eid savings packages in Parung Subdistrict Subang Subang Regency, and the impact of the implementation of Eid savings packages in Parung Village Subdistrict Subang Subang Regency, the research method used is qualitative research with an empirical approach. Data collection techniques used were observation, interviews, and documentation. In this study, the data source consisted of Primary Data and Secondary Data. Primary data were obtained from the field results by direct observation and interviews with managers and members of the Eid package in Parung Village, Subang District, Subang Regency. Secondary data was obtained from various references, such as sources from the internet, institutional archives and other readings related to the problem under study. The results showed that the implementation of the Lebaran Package Savings in Parung Village, Subang Sub-District, Subang Regency using the Wadi'ah (savings) agreement as well as the Salam (package) agreement, according to the syari'ah economy this kind of transaction is invalid, because Islam forbids in one transaction there are two contracts at once. However, the presence of Eid savings packages, is very positive contribution to the community, so management should be adjusted to the principles of Islamic sharia. Among them separating savings transactions and Eid packages.
\end{abstract}

Keywords - Savings, Eid Package, Islamic Economy.

I. Pendahuluan

Jual beli paket lebaran adalah transaksi pemesanan barang sembako kebutuhan hidup 


\section{EKSISBANK Vol. 3 No. 2 Desember 2019}

sehari-hari, dimana objek jual beli pesanan tersebut adalah makanan kebutuhan hidup yang dapat dijumpai dipasaran seperti beras, minyak goreng, daging dan lain sebagainya.

Fenomena yang sering terjadi di masyarakat Indonesia yaitu menjelang lebaran kebutuhan pokok akan cenderung naik maka dari itu, demi pemenuhan kebutuhan lebaran terasa ringan, sekarang orang cenderung mempersiapkannya jauh hari sebelum lebaran tiba. Baik dengan cara menabung maupun melakukan pemesanan terhadap barang barang kebutuhan lebaran (Wirdyaningsih, 2005).

Kenaikan harga barang tersebut terjadi karena meningkatnya kebutuhan akan makanan dan minuman serta kebutuhan lainnya yang tidak diimbangi dengan kenaikan jumlah pasokan yang disediakan untuk diperdagankan ke masyarakat, faktor lainnya yaitu perilaku masyarakat saat ramadhan menjadi lebih konsumtif. Secara hukum ekonomi, ketika permintaan yang dibutukan rumah tangga (masyarakat) melebihi penawaran maka harga keseimbangan di pasar akan naik di atas harga biasanya.

Program tabungan paket lebaran di Desa Parung, Kecamatan Subang, Kabupaten Subang, penerapannya seperti akad wadi'ah sekaligus akad Jual beli salam. Tabungan Paket Lebaran merupakan program tabungan yang diadakan setiap tahun juga mempersiapkan pemenuhan kebutuhan lebaran, memberikan kemudahan dalam pemenuhan kebutuhan lebaran terasa ringan.

Pengertian wadi'ah dapat diartikan sebagai titipan murni dari satu pihak ke pihak lain, baik individu maupun badan hukum, yang harus dijaga dan dikembalikan kapan saja si penitip menghendaki (Lubis, 2000).

Dalam aktivitas perbankan tentunya titipan (dalam bentuk simpanan) tersebut tidak disimpan begitu saja oleh perbankan. Akan tetapi bank akan mempergunakannya dalam bidang aktivitas perekonomian dengan ketentuan bank menjamin sepenuhnya untuk mengembalikan simpanan nasabah tersebut apabila dikehendaki (Wiroso, 2005). Wadi'ah semacam ini disebut juga dengan wadi'ah yad-dhamanah.

Sedangkan kontrak pesanan barang dalam lembaga keuangan syari'ah dikenal dengan istilah
Jual beli Salam. Salam yaitu kontrak jual beli pesanan uang dan harga barang dibayarkan secara tunai, sedangkan barang yang dibeli belum ada hanya sifat-sifat, jenis dan ukurannya sudah disebutkan pada waktu perjanjian dibuat harga jual yang telah disepakati dicantumkan dalam akad Salam dan tidak boleh berubah selama berlakunya akad (Karim, 2006).

Adapun dasar hukum pelaksanaan akad Wadi'ah adalah firman Allah SWT. Dalam AlQur'an surat An-Nisa ayat 58 sebagai berikut (Wirdyaningsih, 2005):

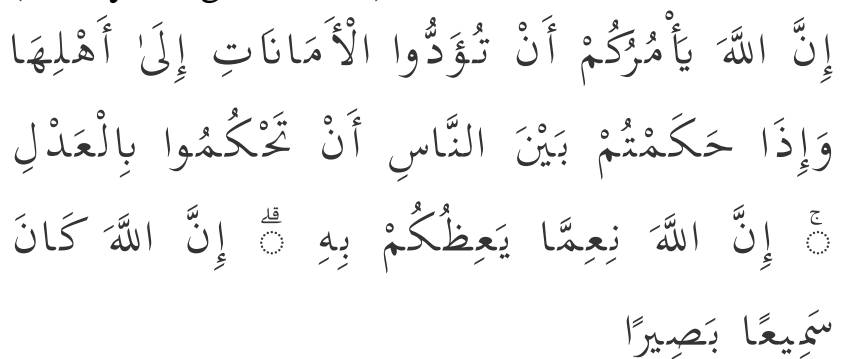

"Sesungguhnya Allah menyuruh kamu menyampaikan amanat kepada yang berhak menerimanya, dan (menyuruh kamu) apabila menetapkan hukum di antara manusia supaya kamu menetapkan dengan adil. Sesungguhnya Allah memberi pengajaran yang sebaik-baiknya kepadamu. Sesungguhnya Allah adalah Maha mendengar lagi Maha melihat".

Dasar hukum pelaksanaan akad Salam dijelaskan juga dalam Al-quran Surat Al-Maidah ayat 1 sebagai berikut (Djuwaini, 2010):

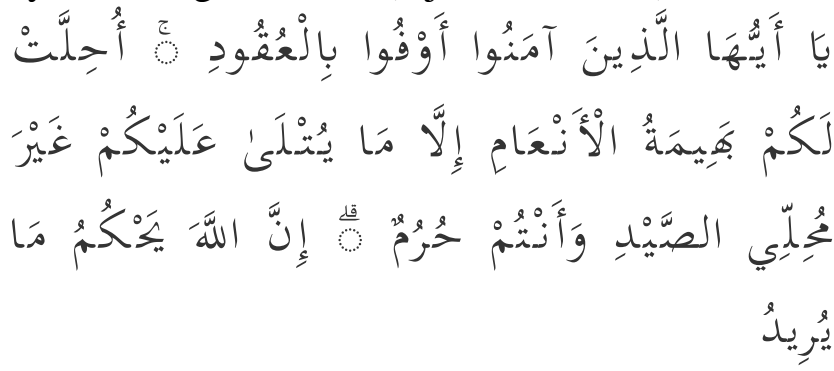

"Wahai orang-orang yang beriman! Penuhilah janji-janji, Hewan ternak dihalalkan bagimu, kecuali yang akan disebutkan kepadamu, dengan tidak menghalalkan berburu ketika kamu sedang berihram (haji atau umrah). Sesungguhnya Allah menetapkan hukum sesuai yang Dia kehendaki.

Dalam pengembalian tabungan berupa barang, yaitu berupa paket kebutuhan lebaran yang harganya disesuaikan dengan jumlah uang yang telah disetorkan. Paket yang akan diterima oleh anggota telah ditentukan di dalam buku tabungan, yaitu berupa pilihan paket yang macam dan 


\section{EKSISBANK Vol. 3 No. 2 Desember 2019}

takarannya sudah ditentukan dan anggota berhak memilih paket sesuai dengan yang dikehendakinya sedangkan sisa dari uang tabungan bisa diambil kembali oleh anggota dan Paket diambil pada H-2 sebelum lebaran.

Jika dilihat dari ketentuan tersebut, akad wadi'ah dalam tabungan paket lebaran termasuk kategori akad wadi'ah yad-dhamanah yaitu tabungan yang dititipkan di kembangkan oleh pengelola. Sedangkan akad Salam dalam tabungan paket lebaran, yaitu pemilihan paket yang spesifikasi barang (macam dan ukuran, pembayaran dan jatuh tempo) telah ditentukan dengan jelas. Akan tetapi spesifikasi kualitas mutu barang tidak ditentukan dengan jelas.

\section{Bagan 2.1}

Kerangka Pemikiran Prosedur Paket Lebaran

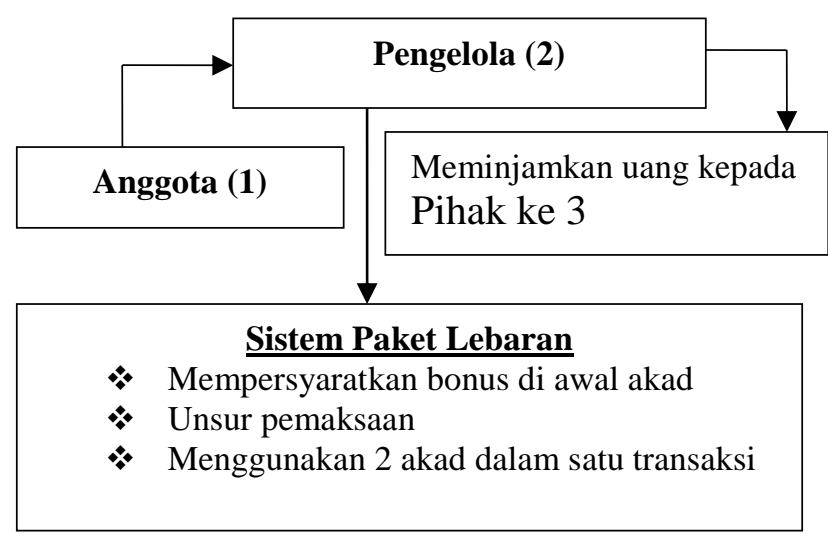

Sumber: Diolah oleh Peneliti Tahun 2019

Teori yang digunakan yang berhubungan dengan penelitian ini adalah teori Hirarki Kebutuhan Maslow (Hidayat, 2011) yang di ungkapkan oleh Abraham Maslow bahwa kebutuhan-kebutuhan dasar manusia di tingkat rendah harus terpenuhi atau paling tidak cukup terpenuhi dahulu sebelum kebutuhan-kebutuhan di tingkat lebih tinggi menjadi hal yang memotivasi.

Konsep Hirarki kebutuhan maslow yaitu :

1. Kebutuhan Fisiologis (Physiological Needs).

2. Kebutuhan akan rasa aman (Safety / Security Needs).

3. Kebutuhan akan rasa memilki dan kasih sayang (Social Needs).

4. Kebutuhan akan Penghargaan (Esteem Needs).
5. Kebutuhan akan Aktualisasi (Selfactualization Needs).

Maksud penulis melakukan penelitian ini adalah :

1. Untuk mengetahui sistem akad dan pelaksanaanya dalam tabungan paket lebaran di Desa Parung Kecamatan Subang Kabupaten Subang;

2. Untuk mengetahui persfektif Ekonomi Syari'ah dalam tabungan paket lebaran di Desa Parung Kecamatan Subang Kabupaten Subang;

3. Untuk mengetahui dampak pelaksanaan tabungan paket lebaran bagi masyarakat Desa Parung Kecamatan Subang Kabupaten Subang.

\section{Metodologi Penelitian}

Metode yang digunakan dalam penelitian ini adalah Metode deskriptif kualitatif yaitu penelitian yang menggambarkan serta menyajikan suatu peristiwa yang terjadi di lapangan dengan menggunakan teknik pengumpulan tringulasi data yaitu melalui observasi, wawancara, dokumentasi, dan juga penelitian kepustakaan dengan membaca buku, jurnal, artikel, website yang berkaitan dengan masalah yang akan diteliti (Bagoes, 2004).

Penelitian deskriptif merupakan penelitian yang berusaha mendeskripsikan sesuatu. Peneliti akan mencari tahu bagaimana Sistem akad yang digunakan dalam pelaksanaan tabungan paket lebaran di Desa Parung Kecamatan Subang Kabupaten Subang. Bagaimana tinjauan ekonomi syari'ah terhadap pelaksanaan tabungan paket lebaran di Desa Parung Kecamatan Subang Kabupaten Subang. Dan Dampak pelaksanaan tabungan paket lebaran di Desa Parung Kecamatan Subang Kabupaten Subang (Arikunto, 2013).

Penelitian yang penulis gunakan menurut tiga studi kasus yang dijelaskan oleh Robert K Yin yaitu penelitian eksplanasi. Karena penelitian eksplanasi dimaksudkan agar peneliti lebih mengetahui dan mengembangkan konsep sesuai dengan keadaan di lapangan. Penelitian ini tidak harus dilakukan oleh orang yang sudah mahir dalam masalah yang diteliti tersebut. Orang atau 


\section{EKSISBANK Vol. 3 No. 2 Desember 2019}

masyarakat sering tidak puas hanya sekedar mengetahui apa yang terjadi, bagaimana terjadinya, tetapi juga ingin tahu mengapa hal tersebut bisa terjadi. Oleh sebab itu penulis bertujuan untuk mengkonfirmasi sebab terjadinya suatu masalah.

Data primer merupakan data yang diperoleh secara langsung oleh penulis dari responden terpilih pada lokasi penelitian. Data primer diperoleh dengan cara wawancara. Pada tanggal 11 Mei 2019 penulis mendatangi Pengelola dan anggota paket lebaran di Desa Parung Kecamatan Subang, berbagai pertanyaan yang penulis tanyakan seperti (Yani, 2019):

Bagaimana sistem kerjasama dalam tabungan paket lebaran, bagaimana syarat ikut serta dalam tabungan paket lebaran, bagaimana prosedur pelaksanaan tabungan paket lebaran, apa akad yang digunakan dalam tabungan paket lebaran, apa saja keuntungan yang diperoleh pengelola dan anggota tabungan paket lebaran, apa yang dilakukan pengelola jika ada anggota yang gugur pada saat mengikuti tabungan paket lebaran, bagaimana pengelola mendapat keuntungan dari tabungan paket lebaran, bagaimana syarat pengajuan pembiayaan atau pinjaman pihak ke 3 atau anggota, bagaimana prosedur pengajuan pembiayaan atau pinjaman kepada pihak ke 3 , bagaimana cara menangani pihak ke 3 atau anggota yang tidak dapat melunasi hutangnya ketika sudah jatuh tempo, apa yang menjadi tujuan pengelola membuka tabungan paket lebaran, bagaimana minat anggota paket lebaran dan peminjam (pihak ke 3), Apa saja manfaat yang di dapatkan oleh anggota paket lebaran dan peminjam (pihak ke 3) di Desa Parung Kecamatan Subang Kabupaten Subang.

Adapun data sekunder merupakan data yang diperoleh dari jurnal, skripsi, situs internet, serta bacaan lain yang berhubungan dengan penelitian yang digunakan sebagai data penunjang (Ghony \& Almanshur, 2012).

Adapun teknik pengumpulan data yaitu yang pertama observasi yaitu dengan melakukan pengamatan langsung terhadap objek yang diteliti, Kemudian wawancara merupakan pertemuan dua orang untuk bertukar informasi melalui tanya jawab dengan mengajukan pertanyaan yaitu pengumpulan data yang dilakukan dengan cara memberikan daftar pertanyaan kepada pengelola dan anggota tabungan paket lebaran, serta tokoh masyarakat yang mengetahui dan faham mengenai praktik tabungan paket lebaran.

Setelah mendapatkan data kemudian menggunakan tringulasi data yaitu tenik pemeriksaan keabsahan data dengan mencari tahu sesuatu hal yang lain diluar data yang ada untuk keperluan pengecekan atau sebagai pembanding. Teknik tringulasi ini digunakan sebagai pemeriksaan melalui sumber lain. Dengan dilengkapi penelitian yang dilakukan dengan cara pengumpulan data, melalui bahan-bahan kepustakaan berupa tulisan-tulisan ilmiah, jurnal, laporan penelitian, buku-buku, dan sumber lain seperti internet dan surat kabar yang berhubungan dengan topik yang diteliti.

Kemudian penulis melakukan analisis data merupakan upaya untuk mencari secara sistematis hasil observasi, wawancara untuk meningkatkan pemahaman penelitian tentang kasus yang diteliti.

\section{III.HASIL DAN PEMbahasan}

Hasil dari analisis data yang dilakukan di Desa Parung Kecamatan Subang Kabupaten Subang yaitu, bahwa dalam perspektif ekonomi syari'ah, tabungan paket lebaran di Desa Parung Kecamatan Subang Kabupaten Subang menggunakan akad wadi'ah sekaligus Jual beli salam.

Bila dilihat dari segi operasionalnya, Tabungan Paket Lebaran bergerak dalam kegiatan tabungan sekaligus usaha pengadaan barang-barang kebutuhan lebaran (merupakan kontrak jual beli pesanan paket lebaran). Menurut Islam, perusahaan atau institusi bisnis yang diterapkan transaksi yang mengandung gharar tidak diperbolehkan, karena al-Qur'an melarang dengan tegas transaksi bisnis yang mengandung unsur ketidakpastian dalam bentuk apapun (Rahman, 1996).

Akad didefinisikan sebagai pertalian antara ijab dan qabul yang dibenarkan oleh syara' yang menimbulkan akibat hukum terhadap obyeknya.

Wadi'ah adalah akad penitipan barang/uang antara pihak yang mempunyai barang/uang (mawaddi') dengan tujuan untuk menjaga keselamatan, keamanan serta keutuhan barang/uang.

Akad wadi'ah yang terjadi dalam pelaksanaan Tabungan Paket Lebaran di Desa Parung Kecamatan Subang Kabupaten Subang adalah dana setoran dari anggota yakni Rp. 15.000,- di 


\section{EKSISBANK Vol. 3 No. 2 Desember 2019}

tiap minggunya yang dititipkan kepada pengelola. dengan tujuan untuk menjaga dan keamanan dan keutuhan dana tersebut dalam pelaksanaan tabungan paket lebaran di Desa Parung Kecamatan Subang Kabupaten Subang dalam ketentuan tabungan paket lebaran yaitu selama 44 Minggu (Mamah, 2019).

Akad wadi'ah yang terjadi dalam pelaksanaan tabungan paket lebaran di Desa Parung Kecamatan Subang Kabupaten Subang termasuk kategori prinsip wadi'ah yad-dhamanah di mana semua keuntungan yang dihasilkan dari dana titipan tersebut menjadi milik pengelola, karena berperan sebagai pihak penanggung seluruh kemungkinan kerugian. Sebagai imbalan si penyimpan (anggota) mendapatkan jaminan keamanan. Akan tetapi, ketentuan dalam bonus telah mensyaratkan di awal akad bahwa anggota tidak akan mendapatkan bonus.

Sedangkan akad salam dalam pelaksanaan tabungan paket lebaran di Desa Parung Kecamatan Subang Kabupaten Subang yaitu berupa paket kebutuhan lebaran yang spesifikasinya telah disebutkan dalam akad (baik macam, ukuran, harga, sistem pembayaran maupun jatuh temponya). Ketentuan dalam salam adalah barang yang ditransaksikan harus jelas spesifikasinya (baik jenis, jumlah, kualitas maupun kuantitasnya).

Akan tetapi, adanya akad wadi'ah yaddhamanah sekaligus akad salam dalam pelaksanaan tabungan paket lebaran di Desa Parung Kecamatan Subang Kabupaten Subang menjadi suatu hal yang perlu dianalisis, menurut Adiwarman Karim transaksi semacam ini disebut shafqatayn fi shafqah (dua akad sekaligus atau two in one). Ini terjadi apabila satu transaksi diwadahi dua akad sekaligus. Sehingga tidak ada kepastian (gharar) akad mana yang harus digunakan.dapat dikatakan transaksi semacam ini tidak sah.

Dalam istilah lain transaksi semacam ini disebut dengan al-'aqadain fi al'aqad atau albai'an al-bai'ah yang berarti dua akad yang terkumpul dalam satu transaksi. Ibn Mas'ud menuturkan bahwa Nabi saw pernah bersabda sebagaimana disebutkan dalam hadits:

$$
\text { هَى رَسُولُ اللَّهِ عَنْ صَفْقَتَنْنِ فِي صَفْقَةِة وَاحِدَةٍ }
$$

"Rasulullah saw melarang dua transaksi dalam satu akad”. (HR. Ahmad, al-Bazar dan athThabrani).

Akan tetapi, pelaksanaan tabungan paket lebaran di Desa Parung Kecamatan Subang Kabupaten Subang menurut penulis akan sesuai dengan ketentuan syari'at Islam, jika hanya menggunakan salah satu dari kedua akad tersebut. Jika menggunakan akad wadi'ah yadh-dhamanah maka sebaiknya bonus tidak ditentukan di awal akad dan pengembalian tabungan berupa sejumlah uang yang dititipkan bukan berupa barang.

Dan jika menggunakan akad salam sebaiknya akad yang digunakan adalah cicilan paket lebaran bukan tabungan paket lebaran dan harus menyebutkan merek dalam paket lebaran agar diketahui, kualiatas dan kuantitas barang tersebut. Dan dipersyaratkan adanya kesepakatan antara pengelola dan anggota.

Dengan demikian sekali lagi, selama transaksi berpedoman kepada prinsip-prinsip syari'at Islam dengan terpenuhinya rukun dan syarat yang ada, maka praktek wadi'ah maupun salam menjadi sah, baik dalam akad maupun pelaksanaannya.

\section{IV.KESIMPULAN}

Tabungan paket lebaran di Desa Parung Kecamatan Subang Kabupaten Subang menggunakan akad wadi'ah yadh-dhamanah sekaligus akad salam. Menurut ekonomi syari'ah transaksi semacam ini tidak sah, karena Islam melarang dalam satu transaksi terdapat dua akad sekaligus.

Dalam perspektif Ekonomi Syari'ah Akad wadi'ah yad-dhamanah yang terjadi dalam Tabungan Paket Lebaran, di mana keuntungan dari dana setoran anggota hanya diperuntukkan pengelola. Menurut ekonomi syari'ah seharusnya bonus tidak dipersyaratkan sebelumnya. Sedangkan salam yang terjadi dalam pemesanan paket lebaran, dimana ada beberapa barang yang tidak di sebutkan merk nya dalam daftar paket. Hal ini juga bertentangan dengan ekonomi syari'ah.

Dampak dari pengelolaan paket lebaran ini sangat menguntungkan bagi pengelola khusunya memberi kemudahan kepada anggota untuk 
EKSISBANK Vol. 3 No. 2 Desember 2019

memenuhi kebutuhan terasa ringan dan membantu pihak ke 3 (anggota/Masyarakat Desa Parung) untuk mendapatkan pembiayan pinjaman juga membantu perekonomian toko waserda kelontong di sekitar Desa Parung Kecamatan Subang.

\section{Daftar Pustaka}

Arikunto, S. (2013). Prosedur Penelitian. PT. Asdi Mahasatya.

Bagoes, I. M. (2004). Filsafat Penelitian \& Metode Penlitian Sosial. Pustaka Belajar.

Djuwaini, D. (2010). Pengantar Fiqh Muamalah. Pustaka Pelajar.

Ghony, M. D., \& Almanshur, F. (2012). Metodologi penelitian kualitatif. Ar-Ruzz Media.

Hidayat, R. (2011). Teori dan Aplikasi Psikologi Kepribadian dalam Konseling. Rake Salasin.

Karim, A. (2006). Analisis Fiqh dan Keuangan. Raja Grafindo Persada.

Lubis, S. K. (2000). Hukum Ekonomi Islam. Sinar Grafika.

Mamah. (2019). Pengelolaan Tabungan Paket Lebaran di Desa Parung Subang.

Rahman, F. (1996). Doktrin Ekonomi Islam, Penerjemah Soeroyo Nastangin. Dana Bhakti Wakaf.

Wirdyaningsih. (2005). Bank dan Asuransi Islam di Indonesia. Kencana.

Wiroso. (2005). Penghimpunan Dana dan Distribusi Hasil Usaha Bank Syari'ah. Grafinda Persada.

Yani. (2019). Pengelolaan Tabungan Paket Lebaran. 